\title{
Association between periodontitis and all- cause and cancer mortality: retrospective elderly community cohort study
}

\author{
Ping-Chen Chung ${ }^{1}$ and Ta-Chien Chan ${ }^{2,3^{*}}$ (D)
}

\begin{abstract}
Background: Periodontal infection induces inflammation, which may increase the risk of tumor-promoting effects. The aim of this study was to assess the association between periodontitis and all-cause mortality, and all-cancer and specific cancers' mortality in a health examination cohort of the elderly in the communities.

Methods: A dataset of health examinations for the elderly with cause of death from 2005 to 2012 was obtained from the Department of Health, Taipei City Government. We enrolled 82,548 study participants with 262,035 visits. A Cox proportional hazards model and Cox frailty model were used for calculating the hazard ratios under different periodontal status by using SAS and Rstudio.

Results: Being male, elderly, having a low education level, and smoking were risk factors for mortality in this retrospective elderly community cohort study. Participants with periodontitis followed across time had significantly higher hazard ratios (HRs) for all-cause mortality and all-cancer mortality (HR=1.092, 95\% confidence interval (Cl): 1.038 to $1.149, \mathrm{HR}=1.114,95 \% \mathrm{Cl}: 1.032$ to 1.203 , respectively) in the Cox frailty models after adjusting for age, marital status, education level, sex, and smoking status. After adjusting for age and sex, the hazard ratio was 1.185 ( $95 \%$ Cl: 1.027 to 1.368$)$ for lung cancer mortality, and 1.340 (95\% Cl: 1.019 to 1.762 ) for prostate cancer mortality in the periodontitis group with each visit.

Conclusions: The findings indicated that being male, having a low education level, and daily smoking were risk factors for mortality, and showed mixed evidence that periodontal disease is associated with all-cause, all-cancer and specific-cancer mortality including lung and prostate cancer. We suggest the importance of regular health screening in order to achieve early disease detection and lower mortality risk.
\end{abstract}

Keywords: Periodontitis, Cancer, Mortality, Smoking

\footnotetext{
* Correspondence: dachianpig@gmail.com

${ }^{2}$ Research Center for Humanities and Social Sciences, Academia Sinica, 128

Academia Road, Section 2, Nankang, Taipei 115, Taiwan

${ }^{3}$ Institute of Public Health, School of Medicine, National Yang-Ming

University, Taipei, Taiwan

Full list of author information is available at the end of the article
}

(C) The Author(s). 2020 Open Access This article is licensed under a Creative Commons Attribution 4.0 International License, which permits use, sharing, adaptation, distribution and reproduction in any medium or format, as long as you give appropriate credit to the original author(s) and the source, provide a link to the Creative Commons licence, and indicate if changes were made. The images or other third party material in this article are included in the article's Creative Commons licence, unless indicated otherwise in a credit line to the material. If material is not included in the article's Creative Commons licence and your intended use is not permitted by statutory regulation or exceeds the permitted use, you will need to obtain permission directly from the copyright holder. To view a copy of this licence, visit http://creativecommons.org/licenses/by/4.0/ The Creative Commons Public Domain Dedication waiver (http://creativecommons.org/publicdomain/zero/1.0/) applies to the data made available in this article, unless otherwise stated in a credit line to the data. 


\section{Background}

Periodontitis is a process in which periodontal bacteria [1] and viruses [2] lead to a host immune-inflammatory response in periodontal tissues that causes periodontal pocket formation, attachment loss and bone loss. Numerous studies have pointed out the relationship between periodontitis and systemic diseases such as cardiovascular disease [3], diabetes [4], respiratory disease, especially chronic obstructive pulmonary disease [5], and chronic kidney disease [6]. Furthermore, periodontitis is also associated with several types of cancers such as lung [7], esophageal [8], pancreatic [9], kidney [10], and haematological cancer [11]. Periodontal infection induces inflammation that may increase the risk of tumor-promoting effects $[12,13]$.

Periodontitis is a serious public health issue throughout the world. In 2010, severe periodontitis was the sixth most prevalent condition globally [14]. Globally, the prevalence of severe periodontitis peaked at age 60 to 64 years old, and the global age-standardized prevalence of severe periodontitis was $9.8 \%$ (95\% uncertainty interval, 8.2 to $11.4 \%$ ) in 2017 [15]. The prevalence of periodontitis significantly increased from $11.5 \%$ in 1997 to $19.59 \%$ in 2013 in Taiwan. The pattern of mean age for periodontitis decreased from 1997 to 2013 (mean age \pm standard deviation: $54.46 \pm 14.47$ and $45.51 \pm 16.58$ years old, respectively) [16]. A cross-sectional nationwide survey on periodontal conditions in Taiwan between 2007 and 2008 revealed that the prevalence of a value of 3 or greater on the community periodontal index ((CPI) $\geq 3$ ), which is used to measure the periodontal status and record bleeding, calculus and pocket depth, among those 65 to 74 years old and above 74 years old was 72.7 and $76.7 \%$ respectively $[17,18]$. Severe periodontitis is related to poor oral health conditions which can lead to tooth loss, unclear speaking, difficulty chewing and swallowing, poor nutrition, and poor quality of life [19].

Pathogenic microorganisms such as Porphyromonas gingivalis, Treponema denticola and Tannerella forsythia lead to chronic inflammation and destruction of periodontal soft and hard tissues [20]. The spread of bacteria and inflammatory mediators from the oral cavity can elevate and sustain systemic inflammatory conditions and damage to various organs $[9,21]$. The inflammatory reaction directly or indirectly induces cell proliferation and the release of reactive oxygen species and other metabolites that can promote cancer initiation $[21,22]$.

Thus, the primary goal of periodontal therapy is to arrest the inflammatory disease process. Regardless of age, nonsurgical and surgical periodontal treatments for periodontal disease are effective therapies, removing subgingival biofilm and doing plaque control to maintain periodontal health $[23,24]$. The aim of this study was to assess the association between periodontitis and all- cause mortality, all-cancer and specific cancers' mortality in a health examination cohort of the elderly in the communities.

\section{Methods \\ Study design and population}

This was a retrospective cohort study from January 1 , 2005 to December 31, 2012, which used a dataset of health examinations for the elderly with age equal to or above 65 years old, performed by Taipei-contracted hospitals and supported by the Department of Health, Taipei City Government in Taiwan. Participation in the annual health examinations was voluntary for senior citizens. The study population received an interview, physician consultation and clinical examination from January 1, 2005 to December 31, 2008.

Those aged less than 65 years old $(n=853)$, or with a misrecorded examination date $(n=9)$ or missing data on periodontal status $(n=5257)$ at the first visit were excluded. Finally, we enrolled 82,548 study participants for further analyses. The total visits numbered 262,035 as of the end of the study after excluding 26,461 visits with missing data regarding periodontal status $(n=26,455)$ or misrecorded examination dates $(n=6)$ (Fig. 1).

\section{Assessment and definition of periodontitis}

In the oral examination, participants with periodontal status reported as "inapplicable" or "refused" were excluded. If participants' periodontal status as diagnosed by dentists showed "no obvious abnormalities" then these participants were classified as having healthy periodontium, while participants with "abnormal periodontal status" diagnosis and periodontal tissues described as "tooth mobility" or "periodontitis" by dentists were classified as having periodontitis.

\section{Outcome definition}

The primary endpoint was the date of death, especially death from cancer, or the end of the follow-up period (December 31, 2012). The cause of death was recorded according to the International Classification of Diseases, Ninth Revision (ICD-9: 001-998) or Tenth Revision (ICD-10: A00-Z99) [25].

\section{Measurement of exposure and potential confounders}

The baseline interview collected age, sex, education level (illiterate, 1-6 years of schooling, 7-14 years of schooling, or above 14 years of schooling), marital status (married and living together, vs. others), self-reported smoking status in the past 6 months (smoked every day, smoked some days or socially, or did not smoke), and self-reported intake of two fruits and three dishes of vegetables daily (yes, no). If the participant had a history of diabetes or took long-term medication for controlling 
170,714 visits of elderly persons registered in Taipei

health examination for the elderly from $2005-2008$

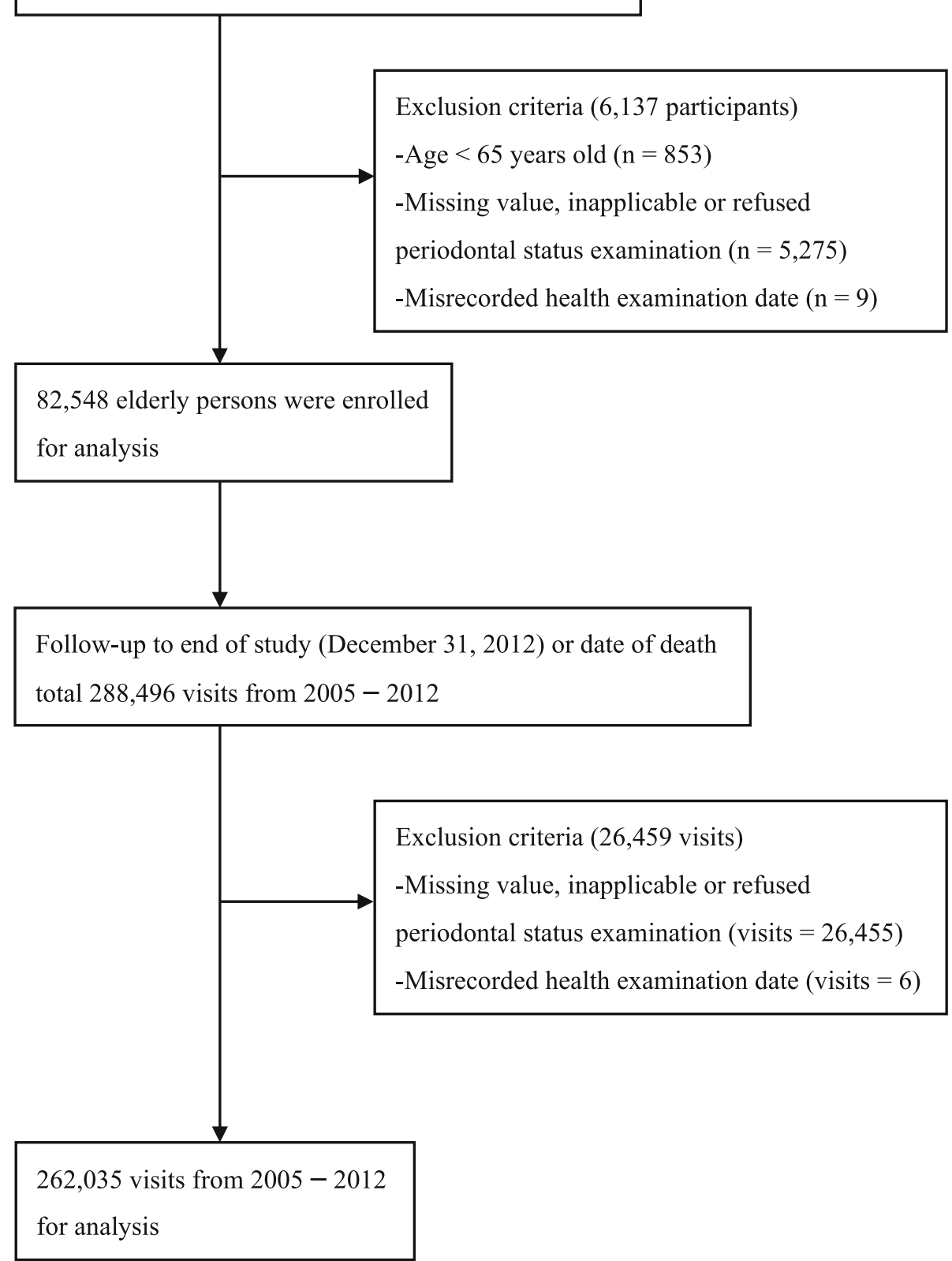

Fig. 1 The flow chart of the study sample enrollment and follow-up

diabetes, or the fasting blood glucose report revealed abnormality, then the participant was defined as diabetic. In each oral examination, periodontal status was recorded by dentists.

\section{Statistical analysis}

The proportions of participants with different periodontal status at the baseline were calculated separately by demographic characteristics and health behaviors.
Comparisons of baseline characteristics between subgroups according to the periodontal status were made using logistic regression in which the first category in each variable was regarded as the reference group. Kaplan-Meier curves with the log-rank test were employed to demonstrate the differences in survival curves in subgroups of different periodontal status at the baseline. At each time point, Kaplan-Meier survival data included the numbers at risk. 
A Cox proportional hazards model [26] and Cox frailty model $[27,28]$ were used for calculating the hazard ratios of all-cause mortality and all-cause cancer mortality under different periodontal status. A Cox proportional hazards model as a semi-parametric model is a common method for study of time-to-event data [26]. A Cox frailty model is a time-dependent model considering random effects of time. This approach can be used for repeated events for the same individual [29]. In our elderly cohort, a participant might be examined in several years, and the smoking and periodontal status might be different each time. The Cox frailty model is a suitable method of analysis. The coefficients estimated from the frailty models might differ from those of the general Cox model if there is a meaningful contribution of the random term. After deleting participants who had one or more missing covariates regarding education level $(n=$ $12,592)$, marital status $(n=1347)$, and smoking status $(n=335)$ in the baseline data, the Cox proportional hazards model and the Cox frailty model estimated the hazard ratio for all-cause and all-cancer mortality and included age, sex, education level, marital status, smoking status and periodontal status. Due to the low number of each specific cancer to test the association, besides periodontal status, the Cox frailty models of deaths from cancer were only adjusted for age and sex. Hazard ratios and 95\% confidence intervals of all-cause, all-cancer and specific cancer mortalities in subgroups are summarized in Table S1. All analyses were two-sided with alpha set at 0.05 . We conducted all statistical analyses by using SAS (version 9.4) and RStudio (Version 1.0.153) with packages of survival [30], and ggplot2 [31].

\section{Results}

\section{Characteristics of the study population}

In the baseline, 24,806 participants had periodontitis (30.05\%). The mean age of the sample at baseline was 73.59 years, and the slight majority were males (52.15\%). More participants had 7-14 years of schooling (43.12\%), were not married and living together (72.95\%), had not smoked in the past 6 months $(90.86 \%)$, ate fruits and vegetables daily $(77.41 \%)$ and were not diagnosed with diabetes (65.8\%). The association of periodontal status with demographic and health behaviors is presented in Table 1. The following are significant based on $p<0.05$. When comparing participants with healthy periodontium to participants with periodontitis, the latter were more likely to be male $(32.98 \%)$, be illiterate $(32.70 \%)$, have higher frequency of smoking (smoke daily 39.82\%) and have no fruit and vegetable intake daily (33.10\%). However, there was no obvious difference $(p>0.05)$ in the percentages between the healthy periodontium group and periodontitis group by marital status and diabetes diagnosis based on univariate logistic regression.
At the end of study, the number of deaths was 11,160 participants, among which about $33.15 \%$ had periodontitis.

As of December 31, 2012, among 82,548 participants the average number of visits was 3.17 times (Fig. 2). The maximum of visits was 8 times, involving 1666 participants $(2.02 \%)$.

\section{Association between periodontal status and risk of all- cause mortality and all-cancer mortality}

At the midpoint of the study (1500 days), the survival probability of the periodontitis group was lower than that of the healthy periodontium group with regard to both all-cause mortality and all-cancer mortality (Figs. 3, 4). Of the 82,548 participants, 7460 of $57,742(12.9 \%)$ in the healthy periodontium group and 3700 of 24,806 (14.9\%) in the periodontitis group died by the end of the study. The estimated rate of overall survival at 3000 days in the Kaplan-Meier analysis was $80.9 \%$ (95\% CI, 80.1 to 81.8 ) in the periodontitis group and $82.3 \%$ ( $95 \% \mathrm{CI}, 81.3$ to 83.3 ) in the healthy periodontium group. There were significant differences in the rates of survival between the two groups $(P<0.001)$.

Of the 82,548 participants, 2362 of $57,742(4.1 \%)$ in the healthy periodontium group and 1153 of 24,806 $(4.6 \%)$ in the periodontitis group died from cancer. The estimated rate of overall survival at 3000 days in the Kaplan-Meier analysis was $93.5 \%$ (95\% CI, 92.9 to 94.1) in the periodontitis group and $94.2 \%$ (95\% CI, 93.7 to 94.7) in the healthy periodontium group. There were significant differences in the rates of survival among the two groups $(P=0.004)$.

Table 2 shows the adjusted association of periodontitis with risk of all-cause mortality and all-cancer mortality in the baseline. After controlling for other covariates, participants with periodontitis had significantly higher hazard ratios (HRs) for all-cause mortality $(\mathrm{HR}=1.077$, 95\% CI:1.027 to 1.130). A multivariate Cox proportional hazards model showed that being male ( $\mathrm{HR}=1.696,95 \%$ CI:1.606 to 1.791), being elderly, and smoking (daily, $\mathrm{HR}=1.253,95 \%$ CI:1.126 to 1.394) were risk factors for all-cause mortality. Participants with a high education level (above 14 years of schooling, $\mathrm{HR}=0.527,95 \% \mathrm{CI}$ : 0.480 to 0.579 ) had lower mortality. In regard to allcancer mortality, after controlling for other covariates, hazard ratios (HRs) of all covariates had the same trend as that this result was not statistically significant for allcancer mortality (HR $=1.036,95 \% \mathrm{CI}: 0.952$ to 1.128$)$.

Table 3 took annual health examinations results per participant into account. With regard to all-cause mortality and all-cancer mortality, there were significant associations with periodontitis ( $\mathrm{HR}=1.092,95 \% \mathrm{CI}: 1.038$ to 1.149 ; $\mathrm{HR}=1.114,95 \% \mathrm{CI}: 1.032$ to 1.203 ) in multivariate Cox frailty models, after controlling for other 
Table 1 Baseline characteristics of elderly participants with different periodontal status in Taipei (2005-2008)

\begin{tabular}{|c|c|c|c|c|c|c|}
\hline & Total & Healthy peric & & Periodontitis & & \\
\hline & $\mathrm{N}$ & $\overline{\mathrm{N}}$ & (\%) & $\bar{N}$ & (\%) & \\
\hline Age $(n=82,548)$ & $73.59 \pm 6.54$ & $73.61 \pm 6.59$ & & $73.54 \pm 6.44$ & & \\
\hline \multicolumn{7}{|l|}{$\operatorname{Sex}(n=82,548)$} \\
\hline female & 39,496 & 28,890 & $(73.147)$ & 10,606 & $(26.853)$ & \\
\hline male & 43,052 & 28,852 & $(67.017)$ & 14,200 & (32.983) & * \\
\hline \multicolumn{7}{|l|}{ Education $(n=69,956)$} \\
\hline illiterate & 4600 & 3096 & $(67.304)$ & 1504 & (32.696) & \\
\hline $1-6$ years & 21,330 & 14,831 & $(69.531)$ & 6499 & $(30.469)$ & * \\
\hline $7-14$ years & 30,162 & 21,458 & $(71.142)$ & 8704 & $(28.858)$ & * \\
\hline above 14 years & 13,864 & 9972 & $(71.927)$ & 3892 & $(28.073)$ & * \\
\hline \multicolumn{7}{|l|}{ Marital status $(n=81,201)$} \\
\hline married living together & 21,966 & 15,315 & $(69.721)$ & 6651 & $(30.279)$ & \\
\hline other & 59,235 & 41,468 & (70.006) & 17,767 & (29.994) & \\
\hline \multicolumn{7}{|l|}{ Smoking status $(n=82,213)$} \\
\hline no & 74,697 & 52,781 & $(70.660)$ & 21,916 & $(29.340)$ & \\
\hline occasionally & 4558 & 2944 & $(64.590)$ & 1614 & $(35.410)$ & * \\
\hline daily & 2958 & 1780 & $(60.176)$ & 1178 & $(39.824)$ & * \\
\hline \multicolumn{7}{|c|}{ Eat fruits and vegetables $(n=81,978)$} \\
\hline no & 18,517 & 12,388 & $(66.901)$ & 6129 & (33.099) & \\
\hline yes & 63,461 & 44,955 & (70.839) & 18,506 & $(29.161)$ & * \\
\hline \multicolumn{7}{|l|}{ Diabetes $(n=82,548)$} \\
\hline no & 54,286 & 38,037 & (70.068) & 16,249 & $(29.932)$ & \\
\hline yes & 28,262 & 19,705 & $(69.723)$ & 8557 & $(30.277)$ & \\
\hline \multicolumn{7}{|c|}{ All-cause mortality $(n=82,548)$} \\
\hline no & 71,388 & 50,282 & $(70.435)$ & 21,106 & $(29.565)$ & \\
\hline yes & 11,160 & 7460 & $(66.846)$ & 3700 & (33.154) & * \\
\hline \multicolumn{7}{|c|}{ All-cancer mortality $(n=82,548)$} \\
\hline no & 79,033 & 55,380 & $(70.072)$ & 23,653 & $(29.928)$ & \\
\hline yes & 3515 & 2362 & $(67.200)$ & 1153 & $(32.802)$ & * \\
\hline
\end{tabular}

*: logistic regression $p$-value $<0.05$

age: mean \pm standard deviation

covariates. Being male, having a low education level and being a smoker were risk factors for both all-cause mortality and all-cancer mortality when considering each visit.

\section{Association between periodontal status and risk of specific cancer mortality}

Comparing mortality of lung cancer in the periodontitis group to the healthy periodontium group, the hazard ratio was 1.185 (95\% CI: 1.027 to 1.368 ) after adjusting for age and sex in a multivariate Cox frailty model (Table S1). After adjusting for age and sex, the hazard ratio was 1.305 (95\% CI: 0.856 to 1.989) for esophageal cancer, 1.019 (95\% CI: 0.790 to 1.313$)$ for pancreatic cancer, 0.960 (95\% CI: 0.789 to 1.168 ) for liver and gallbladder cancer, 1.164
(95\% CI: 0.952 to 1.423 ) for colorectal cancer, and 1.340 ( $95 \%$ CI: 1.019 to 1.762 ) for prostate cancer.

\section{Discussion}

In this large elderly cohort, all-cause mortality and allcancer mortality had positive association with periodontitis after adjusting for age, marital status, education level, sex and smoking status in Cox frailty models. Furthermore, in terms of specific cancers, lung and prostate cancer mortality were higher in the periodontitis group after adjusting for age and sex.

Bacterial biofilm invades the surrounding connective tissue of the gingiva, which may cause periodontitis. Direct or hematogenous spread of microorganisms increases the blood levels of inflammatory mediators, such 


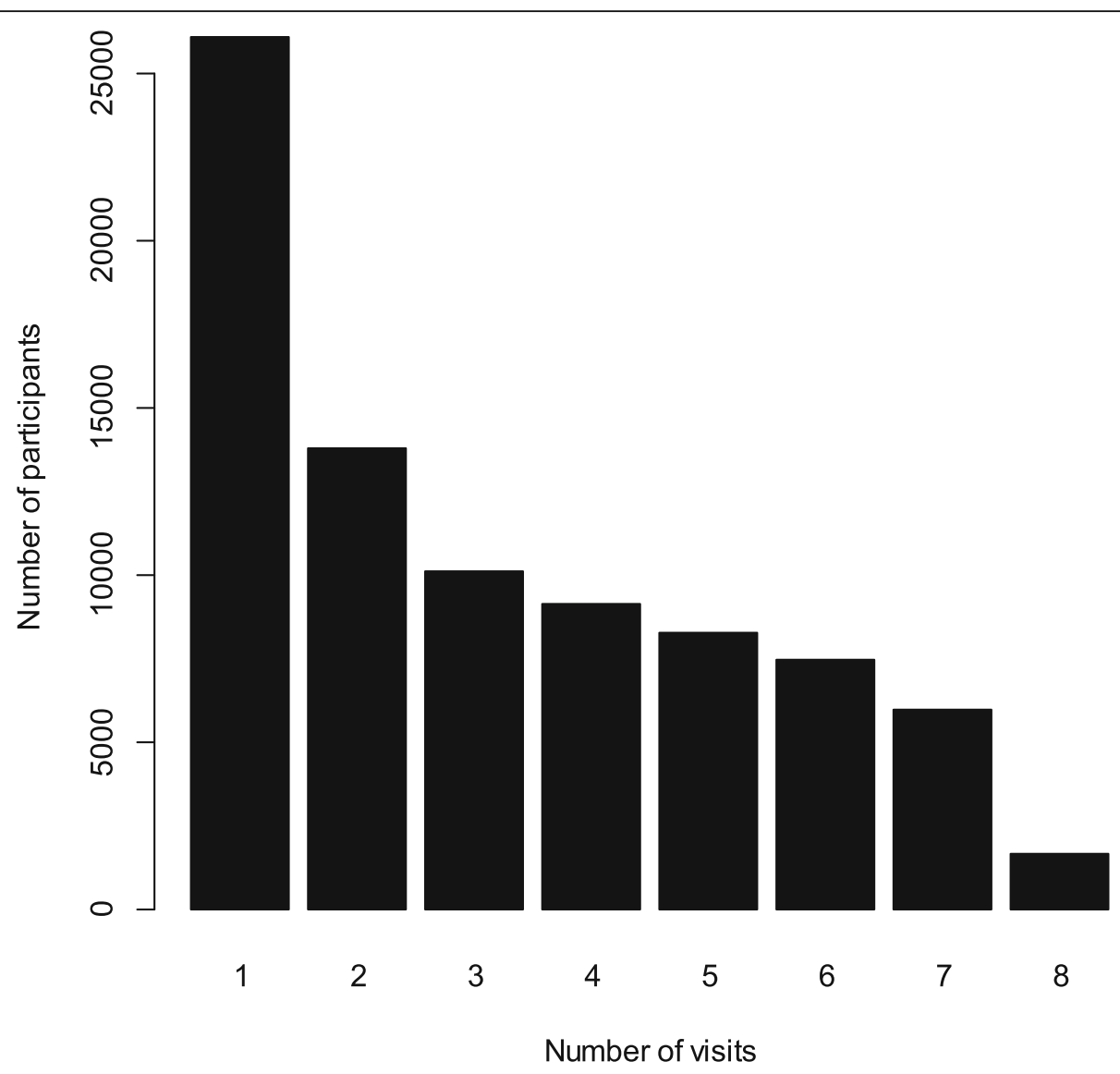

Fig. 2 Distribution of elderly health exam frequency at baseline

Number of visits 


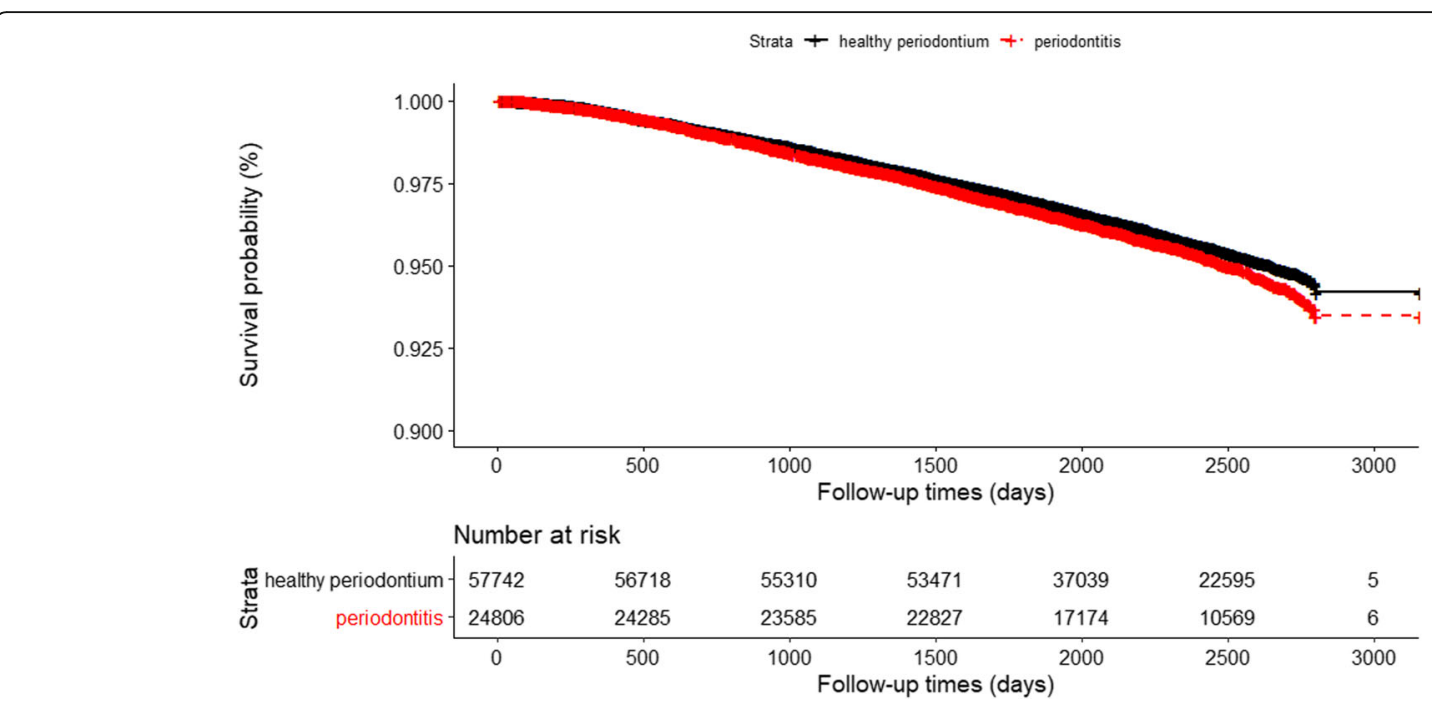

Fig. 4 Kaplan-Meier graph of time to all-cancer mortality by periodontal status

Table 2 Hazard ratios of variables and mortality at baseline by multivariate Cox proportional hazards model

\begin{tabular}{|c|c|c|c|c|}
\hline & \multicolumn{2}{|c|}{ All-cause mortality } & \multicolumn{2}{|c|}{ All-cancer mortality } \\
\hline & \multicolumn{2}{|c|}{$\begin{array}{l}(n=69,528, \\
\text { number of events }=7659)\end{array}$} & \multicolumn{2}{|c|}{$\begin{array}{l}(n=69,528, \\
\text { number of events }=2483)\end{array}$} \\
\hline & Hazard ratio & $95 \% \mathrm{Cl}$ & Hazard ratio & $95 \% \mathrm{Cl}$ \\
\hline \multicolumn{5}{|l|}{ Periodontal condition } \\
\hline healthy periodontium & reference & & reference & \\
\hline periodontitis & $1.077^{*}$ & $1.027-1.130$ & 1.036 & $0.952-1.128$ \\
\hline Age & $1.120^{*}$ & $1.117-1.124$ & $1.078^{*}$ & $1.072-1.085$ \\
\hline \multicolumn{5}{|l|}{ Marital status } \\
\hline married living together & $0.812^{*}$ & $0.772-0.853$ & 0.965 & $0.881-1.058$ \\
\hline other & reference & & reference & \\
\hline \multicolumn{5}{|l|}{ Education } \\
\hline illiterate & reference & & reference & \\
\hline education 1-6 years & $0.787^{*}$ & $0.724-0.856$ & 0.920 & $0.781-1.083$ \\
\hline education 7-14 years & $0.613^{*}$ & $0.564-0.666$ & $0.763^{*}$ & $0.648-0.897$ \\
\hline education above 14 years & $0.527^{*}$ & $0.480-0.579$ & $0.626^{*}$ & $0.523-0.750$ \\
\hline \multicolumn{5}{|l|}{ Sex } \\
\hline female & reference & & reference & \\
\hline male & $1.696^{*}$ & $1.606-1.791$ & $1.719^{*}$ & $1.562-1.893$ \\
\hline \multicolumn{5}{|l|}{ Smoking status } \\
\hline no & reference & & reference & \\
\hline occasionally & $1.576^{*}$ & $1.448-1.715$ & $1.897^{*}$ & $1.653-2.177$ \\
\hline daily & $1.253^{*}$ & $1.126-1.394$ & $1.655^{*}$ & $1.404-1.951$ \\
\hline
\end{tabular}

Abbreviations: $\mathrm{Cl}$ Confidence interval

Variables included in the multivariate Cox proportional hazards model: age, marital status, education level, sex and smoking status

*: $p<0.05$ 
Table 3 Hazard ratios of variables and mortality by multivariate Cox frailty model

\begin{tabular}{|c|c|c|c|c|}
\hline & \multicolumn{2}{|c|}{ All-cause mortality } & \multicolumn{2}{|c|}{ All-cancer mortality } \\
\hline & \multicolumn{2}{|c|}{$\begin{array}{l}(n=245,768, \\
\text { number of events }=7652)\end{array}$} & \multicolumn{2}{|c|}{$\begin{array}{l}(n=245,768, \\
\text { number of events }=6381)\end{array}$} \\
\hline & Hazard ratio & $95 \% \mathrm{Cl}$ & Hazard ratio & $95 \% \mathrm{Cl}$ \\
\hline \multicolumn{5}{|l|}{ Periodontal condition } \\
\hline healthy periodontium & reference & & reference & \\
\hline periodontitis & $1.092^{*}$ & $1.038-1.149$ & $1.114^{*}$ & $1.032-1.203$ \\
\hline Age & $1.106^{*}$ & $1.103-1.110$ & 1.002 & $0.992-1.013$ \\
\hline \multicolumn{5}{|l|}{ Marital status } \\
\hline married living together & $0.782^{*}$ & $0.744-0.822$ & $0.809^{*}$ & $0.683-0.959$ \\
\hline other & reference & & reference & \\
\hline \multicolumn{5}{|l|}{ Education } \\
\hline illiterate & reference & & reference & \\
\hline education $1-6$ years & $0.766^{*}$ & $0.704-0.833$ & 0.740 & $0.538-1.017$ \\
\hline education 7-14 years & $0.592^{*}$ & $0.545-0.644$ & $0.698^{*}$ & $0.510-0.954$ \\
\hline education above 14 years & $0.507^{*}$ & $0.462-0.557$ & $0.573^{*}$ & $0.407-0.806$ \\
\hline \multicolumn{5}{|l|}{ Sex } \\
\hline female & reference & & reference & \\
\hline male & $1.799^{*}$ & $1.704-1.899$ & $2.712^{*}$ & $2.326-3.161$ \\
\hline \multicolumn{5}{|l|}{ Smoking status } \\
\hline no & reference & & reference & \\
\hline occasionally & $1.412^{*}$ & $1.307-1.525$ & 1.126 & $0.956-1.326$ \\
\hline daily & $1.753^{*}$ & $1.469-2.092$ & $1.840^{*}$ & $1.455-2.326$ \\
\hline
\end{tabular}

Abbreviations: $\mathrm{Cl}$ Confidence interval

Variables included in the multivariate Cox frailty model: age, marital status, education level, sex and smoking status

*: $p<0.05$

as lipopolysaccharides and cytokines [32, 33]. The bacteria of dental plaque triggering systemic reactions are thought to lead to malignant transformation in a variety of tissues $[34,35]$. Oral bacteria and inflammation may play a role in carcinogenesis [36]. The present findings show that dental plaque and gingival inflammation are associated with all-cancer mortality [33]. Furthermore, comorbidity and personal health behavior such as smoking status are important risk factors for periodontitis. Patients with periodontitis are more likely to have other systemic disease, an unhealthy lifestyle and low socioeconomic status, which also increases the mortality risk [37].

In our findings, lung cancer and prostate cancer had positive association with periodontitis after adjusting for age and sex. Previous studies were less consistent in finding a relationship between lung cancer and periodontitis. Hujoel et al. in a US-population-based cohort in which periodontal status was defined by standard dental examination, after adjusting for age category and sex, found a positive association between lung cancer mortality and periodontitis (odds ratio $=1.97(95 \% \mathrm{CI}$ : $1.21-3.22))$ [7].
In another study, when comparing lung cancer mortality rates among participants with and without periodontitis defined by whether they had periodontitis treatment procedure codes, the results indicated no significant difference in crude (1.31 (95\%CI: 0.92-1.86)) and adjusted mortality rate ratios $(1.20$ (95\%CI: 0.81-1.80)) which were adjusted for calendar time, age, sex, socioeconomic status, number of teeth, dental treatments, oral health indices, need of periodontal treatment, and diabetes [9]. Arora et al., in a Swedish Twin Registry longitudinal study, suggested a positive association between incidence of prostate cancer and periodontitis classified by self-report after adjusting for potential confounders including sex, age, education, employment, number of siblings, smoking status, smoking status of partner, alcohol status, diabetes, and body mass index (odds ratio $=$ 1.47 (95\%CI:1.04-2.07)) [38]. Periodontal diseases can lead to tooth loss due to inflammatory conditions [39]. Hiraki et al., in a case control study, used tooth loss as an indicator, and a decreased number of teeth remaining was associated with a lower odds ratio for prostate cancer of 0.49 after adjusting for age, sex, smoking and 
drinking status, vegetable and fruit intake, BMI, and regular exercise [40].

However, the associations between some specific cancers and periodontitis are not consistent with previous research, including esophageal, pancreatic, colorectal, liver and gallbladder cancer. One of the reasons might be the low number of esophageal cancer cases $(n=64)$, which made inference uncertain. The lack of an association between periodontitis and other cancers may be due to characteristics of the participants. In some studies, smoking appears to be a confounding factor in risk of cancer, especially for cancers strongly linked to tobacco use such as lung cancer $[7,10,41]$. Hujoel et al. pointed out that when limited to non-smokers, no association between periodontitis defined by standard dental examination and lung cancer mortality was identified after adjusting for age, age squared, race, poverty index, education, and vitamin $\mathrm{A}$ and $\mathrm{C}$; however, when limited to smokers, periodontitis was shown to be significantly associated with lung cancer [7]. For pancreatic cancer, the hazard ratio was not found to be substantially different after adjusting for smoking [10]. Michaud et al. have suggested that smoking is not likely to account for the excess risks at cancer sites such as pancreatic and kidney cancers [10].

Patients with diabetes have higher risk of developing periodontal disease. At the same time, periodontal disease may worsen the glucose control in diabetes patients. Several studies emphasize the impact of diabetes mellitus on subsequent risk of cancer [42-44]. In a Japanese hospital-based longitudinal study, a history of diabetes was associated with cancer risks for all sites for both males and females, controlling for age and potential confounders [45]. Patients with a past medical history of diabetes may have an increased incidence rate of specific cancers, notably pancreatic, liver, and colorectal cancer [44]. Previous studies usually took diabetes into account when exploring the relationship between periodontitis and mortality. One longitudinal population-based health survey showed a hazard ratio of 1.01 (95\% CI: 1.002 to 1.01) for the association between the extent of clinical attachment level $\geq 3 \mathrm{~mm}$ and all-cause mortality after adjusting for age, sex, household income, years of education, body mass index, smoking, physical activity, and dental checkup. However, the findings did not indicate additive interaction of periodontal destruction and diabetes regarding all-cause mortality. Kebede et al. pointed out that despite the reciprocal relationship between periodontal destruction and diabetes, they may be independent risk factors for all-cause mortality [46].

Previous studies have proposed a mechanism by which vitamin $\mathrm{D}$ decreases the risk of periodontal disease and decreases the risk of several cancers [47]. Individuals with less vitamin $\mathrm{A}$ and $\mathrm{C}$ are more likely to have periodontitis [7]. Individuals with less fruit and vegetable intake have increased risk of cancer of specific sites such as oral cancer and gastric cancer [48]. Less intake of fruit and vegetables may be due to tooth loss resulting from advanced periodontal disease [39].

Our limitations include, first, the fact that the models were not adjusted for comorbidities such as respiratory disease, because the dataset didn't record respiratory function and respiratory diseases. Besides, physical activity was missing in 2005 and 2012, so we couldn't include this variable for analysis. Second, the outcome and the exposure could be affected by unmeasured confounding factors. And third, confounders were considered, but measuring bias might exist in self-reported data such as smoking status, alcohol consumption and daily fruit and vegetable intake. Furthermore, the quantity of alcohol consumption was not assessed. The results for alcohol consumption, daily fruit and vegetable intake and other comorbidities including diabetes, hypertension and cardiovascular disease are shown in the supplement (Table S2 and Table S3). Finally, the periodontal status in this study was diagnosed by dentists, not self-reported by the participants. Because our data are secondary data, we don't have information about the consistency of periodontal health assessment, in the form of agreement between dentists.

Within the same age group as our study, the mortality rates in Taipei and nationally in 2012 were 0.62 and $0.67 \%$ respectively. In this study the mortality rate in 2012 was $0.59 \%$, which was slightly lower than the national mortality rate in the same period. The common reasons for non-participation among the elderly were unsuitable timing or location of the health examinations, lacking time, or feeling too sick to participate $[49,50]$. Because the health examinations in our study were performed by Taipei-contracted hospitals in each administrative division in Taipei, citizens had easy access. Nonparticipants in our study might be those with poorer health. Moreover, Taipei is a highly urbanized city, and has a mortality rate lower than the national mortality rate. In urbanized areas, age-standardized mortality rates were lower than those in suburban and rural areas [51]. Our estimates of hazard ratios might be slightly low.

Strengths of our study are the large sample, and the fact that these participants were followed across time. Over $30 \%$ of the sample were diagnosed as having periodontitis at the baseline. Regular health screening seems important due to the high prevalence of this disease. Health screening allows early identification of chronic non-communicable diseases and its risk factors, which easily happen in the elderly. Health screening can lead to the reduction of related complications as well as mortality [52]. Screening for health problems that can emerge in later life could reduce the burden of disease. Regular oral examination can detect the signs and 
symptoms of oral disease early, in particular dental caries and periodontal disease [53]. Lowering periodontitis prevalence may reduce the medical expenditures of health care systems $[14,54]$.

\section{Conclusions}

Being male, having a low education level, and being a smoker were risk factors for mortality in this retrospective elderly community cohort study. Our study findings showed mixed evidence that periodontal disease is associated with all-cause, all-cancer and specific-cancer mortality including lung and prostate cancer. It is suggested that governments enact policies emphasizing health screening for early disease detection and educating people on the importance of regular health examinations.

\section{Supplementary information}

Supplementary information accompanies this paper at https://doi.org/10. 1186/s12903-020-01156-w.

Additional file 1: Table S1. Hazard ratios of different kinds of mortality. Table S2. Hazard ratios of variables and mortality by multivariate Cox proportional hazards model (baseline). Table $\mathbf{S 3}$. Hazard ratios of variables and mortality by multivariate Cox frailty model

\section{Abbreviations}

$\mathrm{Cl}$ : Confidence interval; $\mathrm{CPI}$ : Community periodontal index; HRs: Hazard ratios (HRs)

\section{Acknowledgments}

We gratefully thank the Department of Health, Taipei City Government for allowing use of their data for this study.

\section{Authors' contributions}

TCC conceptualized and designed the study. PCC analyzed the data. All authors contributed to multiple revisions and approved the final manuscript.

\section{Funding}

This research was supported by a grant from the Ministry of Science and Technology, Taiwan (MOST-106-2627-M-001-003) and a grant titled "Multidisciplinary Health Cloud Research Program: Technology Development and Application of Big Health Data" from Academia Sinica. The funders had no role in study design, data collection and analysis, decision to publish, or preparation of the manuscript.

\section{Availability of data and materials}

The raw data are confidential and cannot readily be shared. Researchers need to obtain permission from the Institutional Review Board and apply for access to the data from the Department of Health, Taipei City Government.

\section{Ethics approval and consent to participate}

This study was approved by the Institutional Review Board (IRB) on Biomedical Science Research, Academia Sinica (AS-IRB-BM 15043). This study was designed as a retrospective longitudinal cohort study. Every enrolled participant needed to fill out an informed consent form to authorize the Taipei City Government to process health examination data for the research purpose.

\section{Consent for publication}

Not applicable.

\section{Competing interests}

The authors declare no competing interests.

\section{Author details}

'Department of Dentistry, Puzi Hospital, Ministry of Health and Welfare, Chiayi, Taiwan. ${ }^{2}$ Research Center for Humanities and Social Sciences, Academia Sinica, 128 Academia Road, Section 2, Nankang, Taipei 115, Taiwan. ${ }^{3}$ Institute of Public Health, School of Medicine, National Yang-Ming University, Taipei, Taiwan.

Received: 28 February 2020 Accepted: 1 June 2020

Published online: 09 June 2020

\section{References}

1. Loesche WJ, Grossman NS. Periodontal disease as a specific, albeit chronic, infection: diagnosis and treatment. Clin Microbiol Rev. 2001;14(4):727-52.

2. Grinde B, Olsen I. The role of viruses in oral disease. J Oral Microbiol. 2010. https://doi.org/10.3402/jom.v2i0.2127.

3. Janket SJ, Baird AE, Chuang SK, Jones JA. Meta-analysis of periodontal disease and risk of coronary heart disease and stroke. Oral Surg Oral Med Oral Pathol Oral Radiol Endod. 2003;95(5):559-69.

4. Kinane DF, Marshall GJ. Periodontal manifestations of systemic disease. Aust Dent J. 2001:46(1):2-12.

5. Shen TC, Chang PY, Lin CL, Chen CH, Tu CY, Hsia TC, et al. Risk of periodontal diseases in patients with chronic obstructive pulmonary disease: a nationwide population-based cohort study. Medicine. 2015;94(46):e2047.

6. Ricardo AC, Athavale A, Chen J, Hampole H, Garside D, Marucha P, et al. Periodontal disease, chronic kidney disease and mortality: results from the third National Health and nutrition examination survey. BMC Nephrol. 2015; 16:97.

7. Hujoel PP, Drangsholt M, Spiekerman C, Weiss NS. An exploration of the periodontitis-cancer association. Ann Epidemiol. 2003;13(5):312-6.

8. Abnet CC, Kamangar F, Islami F, Nasrollahzadeh D, Brennan P, Aghcheli K, et al. Tooth loss and lack of regular oral hygiene are associated with higher risk of esophageal squamous cell carcinoma. Cancer Epidemiol Biomarkers Prev. 2008:17(11):3062-8

9. Heikkila P, But A, Sorsa T, Haukka J. Periodontitis and cancer mortality: register-based cohort study of 68,273 adults in 10-year follow-up. Int J Cancer. 2018;142(11):2244-53.

10. Michaud DS, Liu Y, Meyer M, Giovannucci E, Joshipura K. Periodontal disease, tooth loss, and cancer risk in male health professionals: a prospective cohort study. Lancet Oncol. 2008:9(6):550-8.

11. Migliorati CA. Periodontal diseases and cancer. Lancet Oncol. 2008;9(6):510-2.

12. Mantovani A, Allavena P, Sica A, Balkwill F. Cancer-related inflammation. Nature. 2008:454(7203):436-44.

13. Hoare A, Soto C, Rojas-Celis V, Bravo D. Chronic inflammation as a link between periodontitis and carcinogenesis. Mediat Inflamm. 2019;2019. 1029857.

14. Kassebaum NJ, Bernabe E, Dahiya M, Bhandari B, Murray CJ, Marcenes W. Global burden of severe periodontitis in 1990-2010: a systematic review and meta-regression. J Dent Res. 2014;93(11):1045-53.

15. Bernabe E, Marcenes W, Hernandez CR, Bailey J, Abreu LG, Alipour V, et al. Global, regional, and national levels and trends in burden of oral conditions from 1990 to 2017: a systematic analysis for the global burden of disease 2017 study. J Dent Res. 2020;99(4):362-73.

16. Yu HC, Su NY, Huang JY, Lee SS, Chang YC. Trends in the prevalence of periodontitis in Taiwan from 1997 to 2013: A nationwide population-based retrospective study. Medicine. 2017;96(45):e8585-e.

17. Lai H, Su CW, Yen AM, Chiu SY, Fann JC, Wu WY, et al. A prediction model for periodontal disease: Modelling and validation from a national survey of 4061 Taiwanese adults. J Clin Periodontol. 2015:42(5):413-21.

18. Ainamo J, Barmes D, Beagrie G, Cutress T, Martin J, Sardo-Infirri J. Development of the World Health Organization (WHO) community periodontal index of treatment needs (CPITN). Int Dent J. 1982;32(3):281-91.

19. Visscher CM, Lobbezoo F, Schuller AA. Dental status and oral health-related quality of life. A population-based study. J Oral Rhabilitation. 2014;41(6):416-22.

20. Wang GP. Defining functional signatures of dysbiosis in periodontitis progression. Genome Med. 2015;7(1):40.

21. Corbella S, Veronesi P, Galimberti V, Weinstein R, Del Fabbro M, Francetti L. Is periodontitis a risk indicator for cancer? A meta-analysis. PloS One. 2018; 13(4):e0195683.

22. Coussens LM, Werb Z. Inflammation and cancer. Nature. 2002:420(6917): 860-7. 
23. Heitz-Mayfield LJ, Trombelli L, Heitz F, Needleman I, Moles D. A systematic review of the effect of surgical debridement vs non-surgical debridement for the treatment of chronic periodontitis. J Clin Periodontol. 2002;29(Suppl 3):92-102 discussion 60-2.

24. Renvert S, Persson GR. Treatment of periodontal disease in older adults. Periodontol 2000. 2016;72(1):108-19.

25. Fritz A, Percy C, Jack A, Shanmugaratnam K, Sobin L, Parkin D, Whelan SJlcodfo. International classification of diseases for oncology. World Health Organization. 2000 (Third Edition) https://www.who.int/classifications/icd/ adaptations/oncology/en/. Accessed 02 Sept 2019.

26. Cox DR. Regression models and life-tables. J R Stat Soc Ser B Methodol. 1972;34(2):187-220.

27. Ripatti S, Palmgren J. Estimation of multivariate frailty models using penalized partial likelihood. Biometrics. 2000;56(4):1016-22.

28. Therneau TM, Grambsch PM, Pankratz VS. Penalized survival models and frailty. J Comput Graph Stat. 2003;12(1):156-75.

29. Hougaard P. Frailty models for survival data. Lifetime Data Anal. 1995;1(3): 255-73.

30. Therneau TM. A package for survival analysis in S 2015. https://CRAN.Rproject.org/package=survival. Accessed 21 Sept 2019.

31. Wickham H. ggplot2: Elegant Graphics for Data Analysis. New York: Springer-Verlag; 2016.

32. Tomás I, Diz P, Tobías A, Scully C, Donos N. Periodontal health status and bacteraemia from daily oral activities: systematic review/meta-analysis. J Clin Periodontol. 2012;39(3):213-28

33. Adolph M, Darnaud C, Thomas F, Pannier B, Danchin N, Batty GD, et al. Oral health in relation to all-cause mortality: the IPC cohort study. Sci Rep. 2017; 7:44604.

34. Bascones-Martínez A, Muñoz-Corcuera M, Meurman JH. Odontogenic infections in the etiology of infective endocarditis. Cardiovasc Hematol Disord Drug Targets. 2009;9(4):231-5.

35. Söder B, Yakob M, Meurman JH, Andersson LC, Söder P. The association of dental plaque with cancer mortality in Sweden. A longitudinal study. BMJ Open. 2012;2(3):e001083.

36. Whitmore SE, Lamont RJ. Oral bacteria and cancer. PLoS Pathog. 2014;10(3): e1003933.

37. Hansen GM, Egeberg A, Holmstrup P, Hansen PR. Relation of periodontitis to risk of cardiovascular and all-cause mortality (from a Danish nationwide cohort study). Am J Cardiol. 2016;118(4):489-93.

38. Arora M, Weuve J, Fall K, Pedersen NL, Mucci LA. An exploration of shared genetic risk factors between periodontal disease and cancers: a prospective co-twin study. Am J Epidemiol. 2010;171(2):253-9.

39. Hung HC, Colditz G, Joshipura KJ. The association between tooth loss and the self-reported intake of selected CVD-related nutrients and foods among US women. Community Dent Oral Epidemiol. 2005;33(3):167-73.

40. Hiraki A, Matsuo K, Suzuki T, Kawase T, Tajima K. Teeth loss and risk of cancer at 14 common sites in Japanese. Cancer Epidemiol, Biomarkers Prev. 2008;17(5):1222-7.

41. Fitzpatrick SG, Katz J. The association between periodontal disease and cancer: a review of the literature. J Dent. 2010;38(2):83-95.

42. Coughlin SS, Calle EE, Teras LR, Petrelli J, Thun MJ. Diabetes mellitus as a predictor of cancer mortality in a large cohort of US adults. Am J Epidemiol. 2004;159(12):1160-7.

43. Inoue M, Iwasaki M, Otani T, Sasazuki S, Noda M, Tsugane S. Diabetes mellitus and the risk of cancer: results from a large-scale population-based cohort study in Japan. Arch Intern Med. 2006;166(17):1871-7.

44. Shikata K, Ninomiya T, Kiyohara Y. Diabetes mellitus and cancer risk: review of the epidemiological evidence. Cancer Sci. 2013;104(1):9-14.

45. Kuriki K, Hirose K, Tajima K. Diabetes and cancer risk for all and specific sites among Japanese men and women. Eur J Cancer Prev. 2007;16(1):83-9.

46. Kebede TG, Holtfreter B, Kocher T, Meisel P, Dietrich T, Biffar R, et al. Association of periodontal destruction and diabetes with mortality. J Dent Res. 2017;96(1):56-63.

47. Grant WB. Vitamin D, periodontal disease, tooth loss, and cancer risk. Lancet Oncol. 2008;9(7):612-3.

48. Meyer MS, Joshipura K, Giovannucci E, Michaud DS. A review of the relationship between tooth loss, periodontal disease, and cancer. Cancer Causes Control. 2008;19(9):895-907.

49. Tolonen H, Lundqvist A, Jääskeläinen T, Koskinen S, Koponen P. Reasons for non-participation and ways to enhance participation in health examination surveys — the health 2011 survey. Eur J Pub Health. 2017;27(5):909-11.
50. Gaertner B, Seitz I, Fuchs J, Busch MA, Holzhausen M, Martus P, et al. Baseline participation in a health examination survey of the population 65 years and older: who is missed and why? BMC Geriatr. 2016;16:21.

51. Chen BK, Yang CY. Differences in age-standardized mortality rates for avoidable deaths based on urbanization levels in Taiwan, 1971-2008. Int J Environ Res Public Health. 2014;11(2):1776-93.

52. Sazlina SG. Health screening for older people-what are the current recommendations? Malays Fam Phys. 2015;10(1):2-10.

53. Riley P, Worthington HV, Clarkson JE, Beirne PV. Recall intervals for oral health in primary care patients. Cochrane Database Syst Rev. 2013;(12): cd004346.

54. Nazir MA. Prevalence of periodontal disease, its association with systemic diseases and prevention. Int J Health Sci. 2017;11(2):72-80.

\section{Publisher's Note}

Springer Nature remains neutral with regard to jurisdictional claims in published maps and institutional affiliations.

\section{Ready to submit your research? Choose BMC and benefit from:}

- fast, convenient online submission

- thorough peer review by experienced researchers in your field

- rapid publication on acceptance

- support for research data, including large and complex data types

- gold Open Access which fosters wider collaboration and increased citations

- maximum visibility for your research: over $100 \mathrm{M}$ website views per year

At BMC, research is always in progress.

Learn more biomedcentral.com/submissions 